\title{
CERÁMICA Y EPIGRAFÍA PALEOHISPÁNICA DE FECHA PRERROMANA
}

\author{
JAVIER DE HOZ \\ Universidad Complutense. Madrid
}

\begin{abstract}
RESUMEN
Continuación de J. de Hoz: 2002: "Grafitos cerámicos griegos y púnicos en la Hispania prerromana", AEspA 75, 75-91. Tras algunas consideraciones sobre los grafitos en general $(\S 1)$ se estudian los grafitos del sur de la Península Ibérica, con particular atención a los problemas cronológicos $(\S 2)$, los grafitos propiamente ibéricos (\$3), la en ocasiones difícil diferenciación de grafitos de propiedad y marcas comerciales $(\S 4)$ y los problemas de identificación étnica planteados por los grafitos (§ 5). Un addendum está dedicado a algunas novedades fenicias importantes, posteriores a 2002.
\end{abstract}

\section{SUMMARY}

Sequel to J. de Hoz: 2002: "Grafitos cerámicos griegos y púnicos en la Hispania prerromana", AEspA 75, 75-91. After some generalities about graffiti $(\S 1)$, the following categories are studied: graffiti of the south of Hispania, with emphasis on chronological problems, ( $(2)$, Iberian graffiti ( $(3)$, distinction, some times difficult, of owner graffiti and trade marks $(\S 4)$ and problems of ethnic identity posed by graffiti $(\S 5)$. The addendum considers some Phoenician data discovered after 2002.

PALABRAS CLAVE: epigrafía, grafitos, lenguas paleohispánicas, cerámica, cronología, historia económica.

KEY WORDS: epigraphy, graffiti, Paleohispanic languages, pottery, chronology, economic history.

\section{CERÁMICA Y EPIGRAFÍA PALEOHISPÁNICA DE FECHA PRERROMANA}

1. Los epígrafes antiguos son objetos arqueológicos en un doble sentido. En el primario, se trata de objetos históricos que se recuperan como otras piezas arqueológicas a

\footnotetext{
1 Este trabajo se ha redactado dentro de los proyectos financiados por el Ministerio de Educación y Ciencia BFF20000692-C02-01 y BFF2003-09872-C02-01, y constituye la segunda parte de de Hoz: 2002: "Grafitos"; sus datos y conclusiones están básicamente entresacados de mi Historia lingüística de la Península Ibérica y el sur de Francia en la Antigüedad que espero de próxima publicación, donde podrán verse más detalles. Para ciertas cuestiones generales y problemas teóricos del estudio de los grafitos se debe tener en cuenta el artículo citado, en particular pp. 75-7 y 87-8. Como en ese artículo (N)NP significa nombre(s) personal(es).
}

través de la excavación, el hallazgo casual o porque se han conservado en forma de ruina, visibles pero durante mucho tiempo carentes de interés. En un segundo sentido son objetos arqueológicos porque su estudio, antes de llegar al análisis textual, empieza por el mismo tipo de aproximación que otros objetos arqueológicos, contexto, descripción, colocación en series tipológicas, datación por razones técnicas, estratigráficas o formales, deducción de el por qué y el para qué de su existencia a partir de sus meras características físicas. Si esto es así en todos los casos, y de hecho cada vez más se insiste en estos aspectos en relación con epígrafes, por ejemplo lapidarios, que en tiempos tendían a ser estudiados como meros textos, los grafitos sobre cerámica han estado siempre inevitablemente ligados al estudio arqueológico de sus soportes, pero ello no quiere decir, como he señalado en el artículo que constituye la primera parte de éste, que exista siempre una imagen clara de lo que la epigrafía cerámica implica en una determinada cultura antigua, en especial cuando esa epigrafía se expresa en varias lenguas que corresponden a disciplinas filológicas diferentes aunque históricamente se integren en un mismo mundo. Esa es la justificación de estas líneas, sin duda tan prematuras y tan insuficientemente fundadas aunque en aspectos diferentes como lo fueron las del artículo precedente, junto con las cuales pretenden dar un cuadro general de cómo y por qué los distintos habitantes, indígenas o no, de la Hispania antigua que estaban en posesión de una escritura se vieron llevados a utilizar la cerámica como soporte de alguna clase de texto.

Nos ocuparemos aquí de las gentes del territorio tartesio y del SO de la Península ${ }^{2}$, y de los íberos ${ }^{3}$, incluidos los del sur de Francia. Como en el artículo anterior

\footnotetext{
2 No existe un corpus adecuado de esa epigrafía, excepto en lo que se refiere a las lápidas recogidas en MLH IV, que no nos conciernen directamente aquí. Vid. las referencias a los grafitos en $\$ 2$.

Corpus básico en MLH II (sur de Francia) y III (Península Ibérica). Para las inscripciones aparecidas posteriormente vid. en particular Panosa, Ma. I.: 1993: "Nuevas", y publicaciones dispersas, en su mayor parte citadas en Velaza, J.: 1996: "Chronica”; 2001: "Chronica II"; 2001: "Chronica III", y de Hoz, J. \& Luján, E. R.: 2001: "Bibliografía”. Gracias a la amabilidad de J. Untermann en muchos casos podré citar la referencia que estas inscripciones aún no recogidas en MLH tendrán en su día en esa obra; en esos casos la referencia va precedida de asterisco.
} 
tomaré en cuenta sólo los tipos más comunes de grafito y prescindiré de grafitos relacionados con funciones especiales del recipiente; tampoco me ocuparé de las inscripciones pintadas sobre cerámica, ni de los óstraca, de los que existen testimonios en la Península Ibérica y el sur de Francia tanto en griego como en ibérico, ni de los nuevos desarrollos que se producen a partir de la llegada de los romanos, como tampoco de los epígrafes impresos o sellos. El límite cronológico adoptado implica prescindir también de los grafitos celtibéricos y de los raros testimonios de ese género dejados por otros pueblos indoeuropeos.

Básicamente los grafitos con los que vamos a encontrarnos son de propiedad o, digamos, profesionales, relativos al comercio o, en su caso, a la producción de la cerámica, sin que en muchos casos sea posible una clasificación correcta. No me detengo en cuestiones generales ni metodológicas sobre estos tipos porque ya he comentado lo esencial en el artículo citado.

2. El ámbito cultural propiamente tartesio y su periferia inmediata nos han proporcionado algunos grafitos indígenas, fundamental aunque no exclusivamente cerámicos. En el Bajo Guadalquivir podemos mencionar los procedentes del Cabezo de San Pedro, en la ciudad de Huelva, y los del yacimiento del Carambolo, en las afueras de Sevilla.

Por desgracia buena parte de los grafitos del Cabezo de San Pedro no procede de excavaciones regulares sino del aprovechamiento arqueológico de las labores realizadas en la ladera occidental del Cabezo para evitar desplomes ${ }^{4}$. Con posterioridad, en las excavaciones de los años ochenta en las calles Puerto y Méndez Núñez ${ }^{5}$, se hallaron en estratos definibles otros fragmentos cerámicos con grafitos, de los que al menos uno es sin duda un texto paleohispánico aunque muy deteriorado ${ }^{6}$, y más recientemente, en recuperaciones de materiales descontextualizados procedentes de las calles Botica y Méndez Núñez, se añadieron otros fragmentos de los que sin embargo ninguno contiene con total seguridad un grafito paleohispánico ${ }^{7}$; en cuanto al rico material anterior a mediados del s. VIII recuperado del vaciado del solar de

4 El salvamento de estas piezas se debe a dos arqueólogos locales, F. Gómez y K. Clauss. Vid. Blázquez, J. Mª ., et alii: 1970: Huelva.

5 Fernández Jurado, J. \& Correa, J. A.: 1988-89: "Nuevos". Sobre la excavación en general vid. el conjunto de artículos contenidos en el mismo volumen.

6 MLH IV, J(13); en MLH p. 103 se admite que el único signo conservado completo es una $<i>$ tartesia o fenicia, pero la forma es claramente paleohispánica y no conozco ningún paralelo fenicio.

7 González de Canales, F. \& Serrano, L.: 1995: "Consideraciones”. No tomados en consideración en MLH IV. la calle Méndez Núñez $7-13^{8}$, aunque hay varios grafitos fenicios (ver addendum final), sólo ha aparecido un signo equiparable a uno de los grafemas paleohispánicos (op. cit., 136, láms. XXXV.12 y LXI.11), pero se trata de una forma muy común en marcas de contextos preescriturarios —el diábolo- - Todos los grafitos del Cabezo de San Pedro que nos interesan por su probable cronología, excepto uno, se hallan en cerámicas de "retícula bruñida" ", un tipo característico del SO e incluso podríamos decir característicamente tartesio, cuya vida transcurre, en cronología baja (vid. infra) entre el s. IX y comienzos del VI; sin embargo los fragmentos del Cabezo de San Pedro carecen de fecha precisa, más allá de los límites de uso de ese tipo, dadas las condiciones del hallazgo.

El más importante y antiguo de los grafitos de San Pedro $\left(\mathrm{J}\left(12, \mathrm{n}^{\mathrm{o}} 1\right)=\mathrm{EM} 1\right)^{10}$ correspondería, según algunos autores, a la primera fase de habitación que se ha podido definir en el Cabezo, previa a los primeros elementos orientalizantes; sin llegar a una conclusión tan problemática sí puede asegurarse que se utilizó la escritura cuando la cerámica de "retícula bruñida" tenía todavía una gran calidad y no mostraba ningún indicio de degeneración; digamos pues que con seguridad no más tarde del siglo VII, en el que la presencia de contactos orientales se hace claramente patente, aunque subrayo que de momento estoy utilizando cronologías conservadoras que creo acabarán siendo desplazadas por otras más altas, hoy en discusión pero sobre las que todavía no hay un acuerdo claro entre los arqueólogos (vid. el addendum citado).

Los grafitos de Huelva no fenicios que en principio podemos atribuir al período que aquí nos interesa, aunque sin precisar fechas, son como máximo treinta y uno, de los cuales sólo uno, el ya mencionado $\mathrm{J}\left(12, \mathrm{n}^{\circ} 1\right)$, en

8 González de Canales, F., Serrano, L. \& Llompart, J.: 2004: El emporio, y cf. Torres: 2005: "Tartesios".

9 Schubart, H.: 1971: “Acerca”; Ruiz Mata, D.: 1979: “El Bronce"; Pellicer, M.: 1987-88: "La cerámica"; Torres, M.: 2002: Tartessos, 125-30.

10 En lo que sigue la referencia EM reenvía al catálogo de inscripciones en de Hoz: 1976: "Epigrafía", 272-304, y J seguido de un número entre paréntesis a MLH IV pp. 97-113. El tratamiento de estos materiales en MLH IV es bastante ambiguo; se los recoge antes de la edición propiamente dicha de las inscripciones del SO bajo la rúbrica "Inscripciones no admitidas" ( $\S 1.104-7)$ junto con lápidas sepulcrales fragmentarias o perdidas y de lectura inviable, posibles signos sin sentido e inscripciones supuestamente ibéricas meridionales; de todas ellas se da una edición preliminar con una numeración seguida a la que reenvían mis referencias entre paréntesis. En general se excluye que puedan existir inscripciones del ámbito del SO o del tartésico sobre objetos fechables arqueológicamente en fecha temprana. En Untermann: 2000: "Lenguas", 71-2 y no 72-5 del catálogo de la misma obra (pp. 248-9) se insiste en ideas similares y se considera fenicio todo lo que es antiguo. Como se verá, la visión adoptada en éstas páginas depende de una valoración muy distinta de los datos arqueológicos y de historia de la escritura. 
el borde exterior de un cuenco, tiene cierta longitud, cinco signos, dos de ellos fragmentarios, y pudo en su día corresponder a un texto propiamente dicho, mención completa de un NP por ejemplo ${ }^{11}$; el texto J(13) debió tener también cierta longitud, pero su estado de conservación no permite valorarlo; los restantes son meras marcas o abreviaturas, aunque en casos se trate claramente de grafemas, y sólo uno de ellos, que no está grabado sobre "retícula bruñida" sino sobre cerámica parda a torno - interior de un fragmento de plato liso_- puede ser considerado con seguridad como escritura ${ }^{12}$. Es significativo el número relativamente alto de marcas o signos aislados con función de marca que no son fenicios ni griegos, porque muestran el mismo interés por controlar objetos que acompaña, en muchas ocasiones, a los primeros pasos de la escritura sobre materiales duros ${ }^{13}$.

En cuanto a los grafitos del Carambolo ${ }^{14}$, no son sólo escasos — seis - sino de dudoso carácter escriturario

${ }^{11}$ Sin embargo en MLH IV, p. 103 n.34 se consideran estos signos mera decoración; no lo creo porque cada una de las secuencias de trazos realizadas sin levantar el instrumento cortante del barro ya cocido coincide con la forma de un signo paleohispánico, y no parece que existan paralelos para la supuesta decoración en la enorme masa de fragmentos de retícula bruñida hoy día conocidos.

${ }^{12} \mathrm{~J}\left(12, \mathrm{n}^{\circ} 8\right)=\mathrm{EM}$ p. 277,8 . Los dos signos grabados podrían en sí ser paleohispánicos, fenicios o griegos, pero la hipótesis griega en un plato local de tradición fenicia es muy poco económica y la cronología excluye el fenicio por razones paleográficas; el plato en modo alguno puede ser anterior al s. VII y la forma de los signos difícilmente llega hasta el VIII en las series fenicias, más bien serían propios de una inscripción del s. IX o X. En MLH p. 102 n. 32 se me reprocha no haber tenido en cuenta la posibilidad de que se tratase de una abreviatura fenicia; en realidad sí discutí esa posibilidad; como ya he dicho el argumento fundamental es la cronología paleográfica, que sigue pareciéndome que hace la hipótesis fenicia menos económica que la paleohispánica a pesar de los argumentos de Ruiz Cabrero, L. A. \& López Pardo, F.: 1996: "Cerámicas", 158 n. 24, y ello aunque sólo me decido a utilizar ese criterio cuando los indicios son particularmente claros.

${ }^{13}$ En MLH no se hace referencia concreta sino a los que son claramente escritura para negar que lo sean o considerarlos no paleohispánicos; para las marcas vid. de Hoz: 1976: "Epigrafía”, 272-82, $\mathrm{n}^{\circ}$ 2-7 de los que alguno podría ser letra, y n ${ }^{\circ} 9$, letras con seguridad pero puede ser fenicio y más tardío que los restantes; Fernández Jurado, J. \& Correa, J. A.: 1988-89: "Nuevos", figs. 2.2-3, 3.1-6, 4.1-2: también podría haber alguna letra; González de Canales, F. \& Serrano, L.: 1995: "Consideraciones", p. 9 no 1-3 (ilustración en la p. 10) y p. 12, nº 1-5 (ilustración en la p. 13), de los que el $\mathrm{n}^{\circ} 1$ podría ser resto de letra o quizá inscripción fenicia y el no 2 marca comercial griega, el no 4 parece metrológico; además en pp. 10-1 n ${ }^{\circ} 2-4$ los eds. publican como griegas tres letras que podrían ser paleohispánicas.

${ }^{14}$ de Hoz: 1976: "Epigrafía", 282-4; Mederos, A. \& Ruiz Cabrero, L.: 2001: "Los inicios", 105-6, consideran fenicios estos grafitos, a mi modo de ver sin base adecuada. En todo caso se echa en falta en la bibliografía un estudio directo de estos materiales. con la excepción de una única letra que tanto puede ser fenicia como hispánica (EM10), y que está grabada sobre un plato de barniz rojo procedente del llamado Carambolo Bajo, es decir del poblado que se inicia hacia el 700 a. C. En realidad otros yacimientos presentan una situación similar, con algunas marcas cerámicas, posible letra aislada en algún caso, a las que apenas se ha prestado atención cuando no van acompañadas de alguna inequívoca inscripción hallada en el mismo ambiente ${ }^{15}$.

En la zona extremeña hay que señalar el yacimiento de Medellín que ha proporcionado algunos grafitos cerámicos. Una parte de ellos proceden de las excavaciones en el poblado, y han aparecido en una secuencia estratigráfica coherente. Se trata de nueve fragmentos ${ }^{16}$, cuatro de los cuales parecen contener marcas más bién que letras, otro muestra una marca grafemática, y los cuatro restantes soportan sin duda escritura. En uno de estos últimos casos (Almagro-Gorbea: 1977: El Bronce, 268, frg. 994-1001-1024-1040) probablemente se trata de escritura fenicia, y en EM17 (Almagro-Gorbea cit., fig. 95 6573-6574) la duda está, al menos, justificada ${ }^{17}$.

Nos quedan por lo tanto los siguientes testimonios (J(14) sin especificación de las diversas piezas): un fragmento con tres grafemas, mutilados el primero y el tercero, de un plato gris espatulado, procedente de la fase 2b de la estratigrafía en la llamada Cata Este del Teatro, fechado por el excavador entre 625 y 600 a.C. (EM16); un fragmento de urna gris espatulada con dos grafemas enteros, correspondiente a la fase 2 a de la misma estratigrafía, entre 650 y 625 a.C. (EM18), y un fragmento de vaso gris carenado, fabricado a mano y bruñido, procedente éste de las tierras revueltas de las excavaciones del teatro romano, pero que no debe ser posterior al s. VII (Almagro-Gorbea: 1977: El Bronce, 271, frg. MT. s. n.); este fragmento presenta un único signo, curiosamente el mismo que aparece en un fragmento hallado en una cata en el abrigo de la entrada norte de la cueva de Boquique (Valconchero, Plasencia, CC), también parte de un vaso carenado de cerámica bruñida fina, y perteneciente a un conjunto que se fecha entre el s. IX y el VIII ${ }^{18}$. Tanto lo temprano de la fecha como lo aislado del testimonio, en zona tan septentrional, aconsejan prescindir de él.

\footnotetext{
${ }^{15}$ Mederos, A. \& Ruiz Cabrero, L.: 2001: "Los inicios", 106, intentan interpretar como fenicios un par de grafitos de entre los del Cerro Macareno.

${ }^{16}$ Vid. Almagro-Gorbea: 1977: Bronce, 268-74, que contiene, además de los dos casos citados más adelante, un tercer grafito no recogido en EM, el MT. s. n. de la p. 271.

${ }^{17}$ Para Mederos, A. \& Ruiz Cabrero, L.: 2001: "Los inicios", son fenicios el fragmento 994-1001-1024-1040 citado, EM 16, cuya lectura paleohispánica puede verse en EM p. 315, y tal vez EM 19, que obviamente al ser una simple cruz podría ser letra fenicia, griega o paleohispánica, pero también, y es la hipótesis más económica, mera marca.

${ }^{18}$ Almagro-Gorbea: 1977: Bronce, 139 y 273.
} 
Los dos grafitos del s. VII citados serían sin embargo suficiente testimonio como para poder admitir la existencia de escritura no fenicia ${ }^{19}$ en Medellín en esas fechas. La cerámica gris espatulada y a torno está tan generalizada en el yacimiento que nada obliga a considerar las piezas como importaciones, y por lo tanto podemos tomar en consideración estos grafitos como testimonio del conocimiento de la escritura en la zona. Testimonios posteriores han confirmado ampliamente esta conclusión; prescindiendo del hallazgo de una lápida del SO (MLH J.57.1), existe en la necrópolis un cierto número de grafitos, casi todos sobre platos grises, algunos puramente decorativos, otros marcas, en general variantes de aspa de tipos que ya figuraban en las marcas previamente mencionadas ${ }^{20}$, y en dos casos, grafitos de cierta longitud que merecen un comentario más detenido ${ }^{21}$.

Se trata de dos platos de cerámica gris orientalizante, el primero de los cuales $(\mathrm{J}(26))$ pertenece al tipo 1D1a y a la primera fase de la necrópolis ${ }^{22}$, es decir no es posterior a mediados del s. VI. En su interior, además de motivos decorativos y una marca, se grabaron dos inscripciones, una levógira y otra dextrógira, posiblemente por manos diversas, y no relacionables con ninguna lengua conocida. El otro plato, tipo 3A1 de Lorrio, que al parecer carece de contexto arqueológico precisable ${ }^{23}$, contiene una inscripción (MLH J(27)) que, como las anteriores, es de suponer corresponda a un NP pero tampoco tiene paralelos. La importancia de estos platos es grande porque, con mayor nitidez que otros grafitos, demuestran que en fecha temprana, difícilmente después de c. 600 a.C., existía en el SO una escritura utilizada en soportes distintos de las estelas y cuya relación con la inscrita en éstas es un problema mayor en el que aquí no puedo entrar ${ }^{24}$, a la que no parece adecuado lla-

\footnotetext{
${ }^{19}$ La griega es altamente improbable en esa zona y en esas fechas, aunque uno de los dos grafitos (EM18), e incluso, aunque más difícilmente el otro, podrían interpretarse como letras griegas.

${ }^{20}$ Lorrio, A. J.: 1988-89: "Cerámica”, 311.

${ }^{21}$ Agradezco a M. Almagro-Gorbea el que me haya proporcionado dibujos de los grafitos más interesantes de la necrópolis de Medellín. Con posterioridad a la redacción de estas líneas vid. Almagro-Gorbea, M.: 2002: Epigrafía, 108-9; 2004: "Inscripciones", y de Hoz: 2005: "La recepción".

${ }^{22}$ Lorrio, A. J.: 1988-89: "Cerámica”, 311 y fig. 12 de la p. 310; Almagro-Gorbea, M.: 2004: "Inscripciones", 16-8.

${ }^{23}$ Almagro-Gorbea, M.: 2004: "Inscripciones", 19.

${ }^{24}$ Lo lógico sería que los grafitos y la estela de Medellín estuviesen en la misma lengua, pero la estela presenta la típica escritura redundante y los grafitos no, como en general tampoco los restantes grafitos, cerámicos o no, aparecidos en el sur y SO. Untermann, MLH IV, 109, insiste en considerar "suribérica" toda inscripción no redundante de la zona, y separar éstas netamente de las lápidas en escritura del SO. La cuestión es más compleja y por ahora sin solución clara; quizá las lápidas, por su
}

mar suribérica so pena de descargar a la palabra "ibérico" de todo su sentido, y que naturalmente no podía haber nacido en Extremadura, con lo que los grafitos de la zona más puramente tartésica reciben una confirmación que a mi modo de ver no les era necesaria, pero que debiera servir para terminar con las posturas escépticas.

También en la zona del sur de Portugal existen grafitos aunque igualmente escasos y sólo uno de ellos cerámico; se trata de una letra $<\mathrm{i}>$ dextrorsa, único resto precisable de una inscripción grabada sobre un fragmento de un gran recipiente fabricado a torno, procedente del poblado de la cultura del SO de Monte Coito (Ourique, MLH J(11)) ${ }^{25}$.

Por último hay que citar un grafito procedente del SE de la Península, de la Peña Negra de Crevillente, datado por su excavador en la segunda fase del período II del yacimiento ${ }^{26}$, que se extendería entre 700/675 y $550 / 535$ a. C. Se trata de un fragmento de ánfora, de pasta extraña a la zona, procedente tal vez del SO de la Península, con restos de tres signos, de aspecto muy similar a los de las losas del SO, que se leen ]nao[ ${ }^{27}$; ésta es la interpretación al menos que me parece más acorde con el ductus del grafito, pero no es totalmente imposible que se trate de una inscripción fenicia ${ }^{28}$.

No sorprende el pequeño número de grafitos indígenas tempranos en la zona, pero es significativo que esa escasez se mantenga en momentos posteriores al siglo V. De Córdoba procede un fragmento de plato del siglo V o IV con las letras ire[ en el exterior (H.8.1); de Almedinilla un grafito que ha pasado desapercibido y que necesitaría de un estudio sobre el original, aunque posiblemente es de época romana ${ }^{29}$; de Huelva, posiblemente del Cabezo de la Esperanza (EM9, ya citado), la

función, mantengan una variedad más arcaizante, abandonada ya en la mayoría de las inscripciones que nos han llegado sobre otros soportes, quizá convivan dos escrituras diferentes - ¿y dos lenguas? - en un mismo espacio geográfico, pero recientemente he planteado la hipótesis, en cierto modo más económica, de que en las lápidas encontramos simplemente una variante escribal más marcada y solemne, dependiente de prácticas de enseñanza como ocurre en el caso de la puntuación etrusca, pero dentro de la misma escritura (de Hoz: 2005: "La recepción"). Por supuesto no sabemos todavía cual es la auténtica solución.

25 Beirâo y Gomes: 1985: "Grafitos", §§ 2.2 y 3.2. Como en el caso de J(13), en MLH se afirma que la letra podría ser fenicia; no conozco paralelos fenicios.

${ }^{26}$ González Prats: 1983: Estudio, 231 y 275.

${ }^{27}$ González Prats: 1983: Estudio, 231 y lam. 5 de la p. 297. No recogido en MLH.

${ }^{28}$ De los intentos de Mederos, A. \& Ruiz Cabrero, L.: 2001: "Los inicios", por hacer fenicios los grafitos paleohispánicos, éste es el que me parece más defendible; cf. de los mismos AA.: 2000-1: "Transhumancia".

${ }^{29}$ Vaquerizo, D., Quesada, F. \& Murillo, J. F.: 1992: "La cerámica", 95 y cf. 75 . 
base fragmentaria de un tosco plato pardo con restos de signos en dos líneas de escritura tan perdidos que ni siquiera se puede garantizar que no se trate de escritura fenicia ${ }^{30}$; de Portugal, Herdade da Amoreirinha (Caia, Elvas; J(10)), Azougada (Moura) ${ }^{31}$, Santa Olaia (Figueira da Foz) ${ }^{32}$, y al parecer de Cabeço de Vaiamonte (Portalegre) $)^{33}$, marcas o grafitos ilegibles, siendo además las dos últimas localidades, en especial la primera, excesivamente septentrionales como para que se pueda aceptar fácilmente la idea de que en ellas se habría conocido la escritura antes de la latinización.

Hay sin embargo un par de grafitos más significativos, uno portugués, otro de Extremadura, aparte los procedentes de Oretania que por su lengua ibérica corresponden al § siguiente. Del depósito ritual de Garvão (Ourique, Beja), datado entre mediados del s. IV y finales del III, procede un vaso de perfil en S en cuya base hay un grafito de seis signos, cinco diferentes, en una variedad peculiar de la escritura meridional o del SO ya que dos de los signos, entre ellos el repetido, no tienen una transcripción segura ${ }^{34}$. De Villasviejas (CC) procede un fragmento, hallado en un estrato de fines del $\mathrm{V}$ o comienzos del IV, que tiene la peculiaridad de estar escrito por ambas caras ${ }^{35}$, por lo que posiblemente se tratara de un óstracon pero fragmentado, que en realidad tendríamos que separar del tipo de grafitos de que hasta ahora nos hemos ocupado.

Como se ve la epigrafía cerámica no ibérica del sur es escasa, dispersa y difícil de clasificar. Rara vez contamos con grafitos completos que pasen de un par de signos, y rara vez el soporte está lo suficientemente completo como para que podamos sacar conclusiones sobre la relación entre grafito y recipiente. En esas circunstancias podemos sospechar que existen marcas comerciales pero difícilmente demostrarlo. Más claro es el caso de las inscripciones de propiedad, ya que difícilmente pueden ser otra cosa el grafito mayor del Cabezo de San Pedro, los de Medellín o el de Garvão, pero aquí tropezamos con las limitaciones de nuestro conocimiento de la escritura y de las lenguas afectadas, por lo que no podemos decir nada concreto sobre los NNP en cuestión. Más aún, no tenemos criterios, fuera del geográfico, para delimitar lo que pertenece a la escritura y lengua del SO, es decir la de las estelas inscritas, y lo que pertenece al ámbito propiamente tartésico, que en general se suele confundir con

\footnotetext{
30 de Hoz: 1976: "Epigrafia prelatina”, 286 y 278.

31 Beirâo y Gomes:1985: "Grafitos”, 473-80 y 486-7.

32 Rocha: 1908: "Estaçôes", 44-5.

33 Inéditos, cf. Beirâo y Gomes: 1985: "Grafitos”, 465-6.

34 V. H. Correia en De Ulisses: s. d. (1996), 101-6 y 272; Correa, J. A.: 1996 (1998): "Grafito".

35 Hernández Hernández, F. : 1985: "Nuevos grafitos"; Hernández Hernández et alii : 1989: Excavaciones, 128-9.
}

el del SO, pero que a mi modo de ver está representado, con anterioridad a la epigrafía turdetana sobre vajilla (recogida en MLH III bajo la letra $\mathrm{H}$ ) y a las inscripciones monetales de Obulco (A.100), por un puñado de grafitos entre los que sin duda se incluirían los de Huelva, Córdoba y Almedinilla ${ }^{36}$. Los portugueses por el contrario pertenecerían sin duda al mundo del SO, mientras que, dada la lógica posibilidad de solapamientos entre ambos ámbitos culturales, de la que son buena muestra las estelas de Alcalá del Río (J.53) y Puente Genil (J.51), y nuestro desconocimiento de las fronteras lingüísticas entre las gentes del SO, las tartesias y los grupos extremeños, dudo que podamos precisar en mucho tiempo la adscripción de otros testimonios.

3. Los grafitos propiamente ibéricos de propiedad abundan sobre cerámicas valiosas ${ }^{37}$, aunque una vez más en algunos de los casos así interpretados podría tratarse de marcas comerciales al estilo de las griegas y púnicas. Los grafitos están atestiguados en las tres escrituras utilizadas por los íberos, la greco-ibérica, la ibérica levantina y la meridional.

Su distribución es llamativa. De los greco-ibéricos han aparecido uno aislado en los yacimientos de Benillova (G.3.1), Els Baradells (G.4.1), El Puig de Alcoy $(\text { G.2.1 })^{38}$, y Coimbra del Barranco Ancho ${ }^{39}$, y quince, todos ellos sobre cerámica ática de barniz negro, en El Campello (G.9.1-15) ${ }^{40}$. No existen por el momento estudios que recojan los datos relativos a número total de fragmentos de cada uno de esos yacimientos, número de

\footnotetext{
${ }^{36}$ Sobre la diferencia entre epigrafía tartesia y del SO vid. de Hoz: 1989: "El desarrollo", 564-5; 1995: "Tartesio", 595-8. Ideas parecidas en Villar, F.: 2000: Indoeuropeos, 419, cuya interpretación etimológica de los topónimos no afecta al problema de la distribución, y en Torres, M.: 2002: Tartessos, 3267. Ideas diferentes por ej. en Untermann, MLH IV, 156.

${ }^{37}$ Maluquer : 1968: Epigrafía, 56-7, 59-64 y 111-27; Untermann, MLH III.1, 127-8.

${ }^{38}$ El grafito de Tossal de Manises, Llobregat: 1972: Contestania $\mathrm{n}^{\circ} 33$ (p. 128) (G.10.1), debe ser ibérico levantino o romano.

39 de Hoz: 1998: "La epigrafía", 222.

${ }^{40}$ Los cuatro primeros publicados, además de en MLH G.9.1-4, en Llobregat: 1972: Contestania , $\mathrm{n}^{\circ}$ 27-31; los siguientes en Llobregat : 1989: 'Graffiti', no 6-7 (G.9.15 y 8), 10-1 (G.9.12 y 14), 13-8 (G.9.6, 13, 7, 11, 5 y 9). Los no 8 y 9 de Llobregat pueden ser marcas propiamente griegas, 12 y 19 son marcas indeterminadas, 21 y 22 son grafitos púnicos, y en cuanto al $\mathrm{n}^{\circ} 20$ podría ser una forma aberrante de la $s$ greco-ibérica, es decir de sampi, como quiere Llobregat, op. cit. 160-1 —a pesar de que en ese artículo hay una cierta confusión sobre el papel de san y sampi en el alfabeto griego-, pero más probablemente es una de las muchas marcas que se basan en complicaciones caprichosas de la letra alfa. Todos estos grafitos han sido publicados de nuevo, con estudio detallado de los soportes, en García Martín, J. M.: 2003: La distribución, 111-22.
} 
fragmentos contemporáneos de los grafitos, número de fragmentos de cerámica ática de barniz negro, todo ello comparado con el número de grafitos, pero es significativa la concentración en El Campello que no puede explicarse sólo por las excavaciones regulares allí practicadas, ya que también existen excavaciones regulares en otros yacimientos donde ha aparecido epigrafía greco-ibérica, como El Cigarralejo o Coimbra del Barranco Ancho, y sin embargo sólo han proporcionado algún epígrafe aislado. El comportamiento especial del yacimiento de El Campello desde el punto de vista epigráfico puede explicarse porque efectivamente se trata de un yacimiento especial, si hemos de aceptar las conclusiones de uno de sus investigadores, según el cual "se puede lícitamente inducir que el poblado de la Illeta dels Banyets fue una especie de emporio en el que se establecía el mercado bajo la protección de los dioses" ${ }^{41}$, lo que como veremos encaja muy bien con la abundancia de grafitos, y con el hecho de que éstos no sólo sean greco-ibéricos sino también púnicos y mercantiles en sentido amplio ${ }^{42}$.

En escritura meridional existen también algunos grafitos cerámicos de propiedad, supuestamente un fragmento saguntino (G.12.2), un breve grafito de Toya (H.4.1), ambos problemáticos por motivos diversos y el primero en realidad no meridional (balkatin en escritura levantina), el difícil grafito de la Cova del Sapet (Pego) (MLH III.1, 102), y los nuevos fragmentos de Giribaile ${ }^{43}$, Porcuna $\left(*\right.$ H.12.3) ${ }^{44}$ y Baeza $\left(*\right.$ H.14.1) ${ }^{45}$, pero no existe por ahora ningún yacimiento que presente una concentración comparable con la de El Campello. Hay sin embargo dos grafitos más explícitos, sin duda de propiedad, ambos de la zona oretana a los que ya he aludido. El primero se encuentra sobre el labio de una olla de baja fecha hallada en Giribaile (J, H.11.1) ${ }^{46}$, Su texto es biuniusen, que puede ser interpretado de dos formas, la más probable

\footnotetext{
${ }^{41}$ Llobregat, art. cit., 162. Interpretación distinta y menos probable a mi modo de ver, aunque también adecuada a la hipótesis que aquí defiendo, es la mantenida por M. Almagro, por ej. en 1992: "Las necrópolis", 43. El carácter de puerto comercial de La Illeta es sistemáticamente defendido en García Martín, J. M.: 2003: La distribución.

${ }^{42}$ Aparte de las marcas ya mencionadas en una nota anterior, G.9.4 contiene también, junto al grafito greco-ibérico, una marca y un grafito mercantil seguro.

${ }^{43}$ Gutiérrez Soler, L. M ${ }^{\text {a: }}$ 2002: El oppidum, 176.

${ }^{44}$ Arteaga, O. \& Correa, J. A. : 1994: "Inscripción”; Rodríguez Ramos: 2002: "La inscripción". En realidad Porcuna, a juzgar por las leyendas monetales de Obulco (A.100), debía ser lingüísticamente turdetana, pero el grafito en sí no permite ninguna atribución precisa; en Obulco hay algún NP ibérico, y provisionalmente encuadraré el grafito con los restantes de la provincia de Jaén.

${ }^{45}$ Correa : 1989: "Inscripción vascular"; de Hoz : 1994: "Notas", 170-4.

46 de Hoz: 1976: "Epigrafía prelatina”, 302-3.
}

como NP ibérico, *biu(r)-nius (cf. MLH III.1, §§ 7.43 y 7.94), seguido de un sufijo indicador de propiedad ${ }^{47}$, alternativamente como NP latino adoptado por un indígena que lo ha utilizado con un prefijo y el mencionado sufijo, b-Iunius-en ${ }^{48}$. Otro grafito importante, procedente de Cástulo ${ }^{49}$, está grabado sobre un vaso que por las condiciones del hallazgo se puede fechar a comienzos del siglo IV ${ }^{50}$, y su lectura es sosi, es decir abreviatura de un NP ibérico cuyo primer elemento sería el conocido sosin (MLH III.1, § 7.109). Es importante el que en fechas distintas encontremos en Oretania dos testimonios que apuntan ambos a la presencia de la lengua ibérica en esa zona.

En escritura levantina, o ibérica propiamente dicha, existen grafitos aislados, pero existen también yacimientos que ofrecen un panorama especial. Es éste sin ninguna duda el caso de Azaila (E.1), pero no insistiré en él porque cronológicamente no pertenece al mundo que ahora nos interesa; más importancia tiene para nosotros Ensérune (B.1), un yacimiento en las estribaciones de los Cevennes, próximo a Narbona, Béziers y el Mediterráneo, y que dominaba la vía de comunicación entre las penínsulas italiana e ibérica. La epigrafía ibérica parece surgir en el siglo IV, avanzada ya la segunda de las tres fases que se distinguen en la ocupación del yacimiento, cuya cronología inicial es discutida, pero sería necesario contar con un nuevo estudio de las piezas de barniz negro con grafitos más antiguas, que está en progreso pero aún no concluido. En cualquier caso es notable el número de epígrafes, trescientos setenta y dos en MLH II, a los que habría que añadir el plomo recientemente publicado por Solier \& Barbouteau ${ }^{51}$, y restar algunos grafitos no ibéricos sino griegos, como p. e. B.1.4 o B.1.8, y uno etrusco (B.1.2b). Significativa es también la variedad de tipos epigráficos, que incluye sobre todo grafitos cerámicos, en torno a trescientos cincuenta en soportes muy diversos, pero también sellos sobre dolia y ánforas, fichas de barro, y una tablilla de plomo. Aun cuando una vez más el número de grafitos guarda relación con la intensidad de la excavación, y volvemos a encontrarnos con datos insuficientes sobre la proporción de número total de fragmentos y grafitos en los yacimientos de la zona, la presencia de la escritura en Ensé-

\footnotetext{
47 Única interpretación considerada en MLH.

${ }^{48}$ El prefijo $b$ - puede deducirse en algunos casos, de los que el mejor conocido queda demasiado apartado de nuestra zona, puesto que se trata de la leyenda de las monedas oscenses, $b$ olska-n (MLH A.40). La posibilidad de que el NP Iunius figurase en el grafito la indicó en primer lugar el Prof. J. Maluquer, cf. de Hoz: 1976: "Epigrafía prelatina", 302.

49 de Hoz : 1994: "Notas".

50 Agradezco a J. M. Blázquez las informaciones que en su día me dió sobre este grafito y su permiso para utilizarlas cuando aún estaba inédito.

${ }^{51}$ Solier, Y. \& Barbouteau, H.: 1988 (= 1990): "Découverte".
} 
rune parece anormalmente alta, y creo que el hecho está directamente condicionado por el papel de "oppidummarché" que en general se suele reconocer al yacimiento ${ }^{52}$. En todo caso la abundancia de grafitos en Ensérune nos permite iniciar el análisis, que sería necesario extender a la totalidad de las inscripciones ibéricas, de las relaciones entre tipos de soporte y grafitos. Los simples grafitos de propietario de Ensérune son unos 260, sin tomar en consideración ánforas y dolia que plantean problemas aparte; no se puede en realidad dar un número exacto porque cabe la posibilidad de que una parte al menos de los grafitos muy breves formados por un par de signos, en especial si están en la base del recipiente, no sean abreviaturas de NNP sino marcas de comercio similares a las que se dan en el ámbito griego y púnico; por ello sólo he incluido en el cómputo los casos que me parecen seguros, pero incluyendo los muy fragmentarios cuando está claro que sólo se han conservado parcialmente y que por lo tanto tenían cierta longitud. De esos grafitos de propiedad corresponden a cerámica ática del s. IV unos $30^{53}$; tampoco se trata ahora de una cifra exacta porque como he dicho, aunque se halla en marcha, falta un estudio actualizado de los materiales y dependemos de las atribuciones publicadas que no son siempre seguras. Comparar el número de grafitos de propiedad sobre cerámicas áticas con el resto de los epígrafes ibéricos de la misma época no es fácil porque no contamos con un inventario válido de las ánforas del s. IV, ni de la cerámica ibérica o local, pero no parece que estos tipos, al menos las piezas inscritas, remonten más allá del s. III ${ }^{54}$; en realidad en esas fechas los grafitos están prácticamente reducidos a la cerámica de importación.

52 J. Untermann, MLH II, 81, citando Gallet de Santerre : 1965: "Civilisations classiques", 627s., y Solier : 1978: "Oppida", 155; aunque falta un estudio actualizado de los hallazgos de Ensérune, sigue siendo fundamental Jannoray: 1955: Ensérune. Maluquer: 1968: Epigrafía, intentó precisar la cronología de muchos de los grafitos, y vid. ahora Rodríguez Ramos: 2004: Análisis, 193-6, 212-6; 1997: "Primeras", 27-8; 2000: "Nuevas", 54-5.

${ }^{53}$ En MLH se reúnen las cerámicas figuradas griegas del s. IV en B.1.1-13 — de las que hay que excluir como no áticas B.1.57-, y en B.1.14-32, como cerámicas de tipo campaniense, las cerámicas áticas de barniz negro del mismo siglo, pero entre las campanienses (B.1.33-240) hay sin duda alguna ática del s. IV (vid. B.1.59, $\mathrm{n}^{\circ} 92$ en el catálogo de Les Ibères : 1997) por lo que he redondeado los 23 grafitos válidos comprendidos en B.1.1-32 en c.30. No he considerado B.1.2, que no creo ibérico ni B.1.4 y 8 que son marcas mercantiles griegas; B.1.1, 2, 3, y 28 llevan además del grafito principal una marca de las que sólo la última parece ibérica. Los números se refieren a piezas con grafito, aunque alguna de ellas $(B .1 .13,15,31)$ tiene más de uno, o lleva además, como acabamos de ver, una marca que puede ser grafemática.

${ }^{54}$ En MLH se consideran piezas de tipo jonio o simplemente jonias a B.1.5-7; se trata de cerámica amarilla jonizante. B.1.6 no es un ánfora sino un anforisco.p
En otras zonas la situación parece ser similar; el caso de Cataluña ha sido estudiado recientemente ${ }^{55}$. Allí casi todos los epígrafes de propiedad tempranos se documentan en cerámicas de figuras rojas o barniz negro, aparte un caso excepcional de figuras negras (C.3.30), y se concentran sobre todo en Ullastret, cuya función de intermediario preferente entre Ampurias y el mundo indígena es probable, y secundariamente en algunos otros centros de relevancia en la circulación de bienes, entre ellos la comunidad ibérica residente en Ampurias.

Posteriormente las cosas no cambian demasiado; frente a unos doscientos grafitos en cerámica campaniense de Ensérune tenemos unos ochenta en cerámicas ibéricas o locales, pero hay que matizar; también tenemos grafitos sobre cerca de una treintena de ánforas y un par de dolia, y un número significativo de los grafitos sobre campanienses podría corresponder a marcas de comercio más que a inscripciones de propietario, mientras que las posibles marcas en los otros tipos cerámicos son escasísimas. De hecho una razón complementaria para pensar que los grafitos formados por uno o dos signos, normalmente en el pie, en raras ocasiones en la pared o el interior de un recipiente, son marcas comerciales, es su rareza en las cerámicas no de lujo; la razón fundamental es sin embargo el paralelo de las marcas griegas, y secundariamente púnicas ${ }^{56}$. En cualquier caso el predominio de las inscripciones de propiedad sobre cerámicas importadas o de lujo frente a los otros tipos es claro y por otro lado comprensible. El aumento de las marcas así como los grafitos sobre los grandes contenedores, a los que habría que añadir los sellos, raros en ánforas pero no tanto en dolia, nos lleva a un aspecto de la evolución de la epigrafía ibérica en su contexto helenístico que, aunque se inicia en el s. III, se desarrollará sobre todo en época romana y por ello no nos ocupará en esta ocasión.

La tipología de los grafitos cerámicos es simple, a menudo no aparece ni siquiera un NP completo y, de no darse una clara coincidencia entre los signos grabados y el comienzo de un elemento onomástico ibérico bien conocido, nos queda la duda de si se trata de una abreviatura o de una marca de otro tipo, que indique no propiedad sino otra indicación útil para los usuarios del recipiente pero desconocida para nosotros. No son raras sin embargo las inscripciones que consisten en un NP completo, y no faltan las que además precisan la propiedad con un sufijo o una cadena de sufijos.

Por otro lado, junto a los grafitos muy breves, que ya hemos visto que pueden ser marcas, existen otras que ni siquiera corresponden a grafemas sino que, como tam-

\footnotetext{
${ }^{55}$ Panosa: 1999: La escritura, 175.

${ }^{56}$ Vid. la primera parte de este artículo, de Hoz: 2002: "Grafitos", passim.
} 
bién ocurre con las marcas griegas, son meros signos abstractos o dibujos convencionales. Es significativo que este tipo de marcas poco explícitas sean con mucho predominantes en vasijas más utilitarias, como las ánforas y tinajas recientemente recopiladas por C. Mata y L. Soria ${ }^{57}$. Ejemplos de abreviaturas que por su extensión pueden ser inscripciones de propiedad son B.1.19, B.1.30, B.1.53, B.1.55, o B.1.56; para los grafemas que pueden ser marcas de comercio y las marcas sin valor grafemático vid. el § siguiente.

4. Cuanto peor conocida es una lengua más difícil es separar las inscripciones de propiedad de las marcas comerciales. No es extraño por lo tanto que el estudio de las marcas ibéricas plantee más problemas que el de las fenicias, y muchos más que el de las griegas ${ }^{58}$. Es cierto que algunos grafitos sobre ánforas, y sobre todo grafitos y estampillas sobre dolia nos llevan claramente al mundo comercial, pero la mayor parte de este material es de fecha para mí imprecisable o romana. Existen piezas anteriores desde luego; por citar un caso evidente el yacimiento de Pech-Maho fue abandonado a fines del siglo III ${ }^{59}$ y de él proceden ánforas (B.7.9-30) ${ }^{60} \mathrm{y}$ dolia inscritos (B.7.31 y 33) ${ }^{61}$, y dolia con estampilla ibérica $(B .7 .32)^{62}$, aunque no dipintos industriales o mercantiles; de hecho es sintomático que los dipintos de PechMaho, que pueden compartir el espacio sobre una ánfora greco-itálica con grafitos ibéricos, presenten siempre letras latinas ${ }^{63}$. Por otro lado, incluso sobre un contenedor, un NP ibérico claramente inscrito nos deja en la duda de si estamos ante un dato de la comercialización o ante el nombre del propietario en cuya casa se usaba el recipiente; a veces en una excavación realizada con garantías aparecen en un mismo espacio más de un contenedor con un mismo NP, probablemente el de la persona a la que pertenecía ese espacio (por ej. B.7.11 y 12, y quizá 13). Incluso las indicaciones numerales, al menos en un contenedor, no son indicio seguro de marca comercial porque el propietario ha podido tener interés en dejar constancia de la capacidad de su recipiente para recordarla, de la misma forma que los propietarios de vajilla de plata dejaban constancia de su peso. No cabe duda del caracter comercial o industrial de los grafitos, sin embargo, cuando varias marcas diversas se acumu-

\footnotetext{
${ }^{57}$ Mata, C., Soria, L.: 1997: "Marcas".

58 Algunas observaciones en Panosa: 1999: La escritura, 165-73.

59 Solier: 1979: "Découverte d'inscriptions", 119-21; Solier, Y \& Barbouteau, H.: 1988 (= 1990): "Découverte", 67-8.

${ }^{60}$ Solier : 1979: "Découverte d'inscriptions", 95-7.

61 Solier, op. cit., 104.

${ }^{62}$ Solier, op. cit., 103.

63 Solier : 1979: "Découverte d'inscriptions", 93
}

lan sobre un mismo contenedor, como por ej. en el ánfora de Ensérune B.1.335, y es la hipótesis más probable incluso cuando se trata de una sola marca o de una indicación epigráfica muy breve formada por uno o dos grafemas; un repertorio que incluye estos casos puede verse en el trabajo ya citado de Mata y Soria, en el que si las marcas de fecha romana son mayoritarias, también se encuentran bastantes prerromanas ${ }^{64}$.

Los problemas son mayores cuando se trata de vajilla de uso cotidiano; es éste un tema prácticamente por explorar y no tiene sentido por el momento pretender separar el estudio de los grafitos mercantiles ibéricos de los de propiedad, pero de acuerdo con lo dicho más arriba es probable que un cierto número de marcas ibéricas sobre cerámicas de barniz negro, y posiblemente también sobre otros tipos menos frecuentemente inscritos, corresponda a esta categoría. De hecho ya señalé en su día que incluso una copa Cástulo aparecida en Huelva parece llevar un grafito comercial ibérico, lo que es un dato significativo sobre el papel de los indígenas en la redistribución de la cerámica griega en occidente ${ }^{65}$. Grafemas que podrían ser marcas de comercio se encuentran en B.1.11, B.1.12, B.1.32, B.1.38, B.1.57, o B.1.76-85.

5. En la primera parte de este trabajo llamé la atención sobre un interesante caso de grafito sepulcral fenicio en un contexto puramente ibérico, y sobre la posibilidad de que algunos grafitos fenicios contuviesen NNP no fenicios ${ }^{66}$. También el mundo ibérico conoce una digamos disonancia entre los NNP y el contexto en que aparecen. A veces se trata de NNP no ibéricos en escritura ibérica; cuando esos NNP corresponden a una onomástica conocida y controlable, como ocurre en el sur de Francia con los NNP galos ${ }^{67}$, tenemos un testimonio positivo e indiscutible; en otros casos el testimonio es negativo, simplemente podemos decir que el NP no corresponde a la onomástica ibérica, que conocemos relativamente bien ${ }^{68}$, y que debe pertenecer a otra varie-

\footnotetext{
${ }^{64}$ Mata, C. \& Soria, L.: 1997: "Marcas".

65 de Hoz: 1994: "Griegos”, 258-9.

66 de Hoz: 2002: "Grafitos", 79 y 86.

${ }^{67}$ Untermann, J.: 1969: "Lengua”; Correa: 1993: “Antropónimos".

${ }^{68}$ El punto de partida de la comprensión de los NNP ibéricos está en Schuchardt, H.: 1909: "Iberische"; después son fundamentales los trabajos de Untermann: 1987: "Repertorio"; 1990: MLH III.1, 195-238, que pueden ser completados con los de Rodríguez Ramos como 2002: "Problemas", y 2004: Análisis, 344-55, sintetizados en 2002: "Índice crítico". Faria ha dedicado numerosos artículos a la onomástica ibérica, no todos recogidos en la bibliografía de este artículo, en los que comenta los progresos de la investigación, proponiendo a menudo nuevos elementos onomásticos que sin embargo pecan de criterios de identificación excesivamente laxos.
} 
dad lingüística que podría ser la hablada por el portador del NP ${ }^{69}$; esta situación no es infrecuente en Cataluña y el valle del Ebro, pero sí en la región valenciana ${ }^{70}$. Los NNP no ibéricos en inscripciones ibéricas pueden implicar simplemente que un no íbero, conocedor de la escritura ibérica, ha utilizado ésta para reflejar su NP en cierto modo en abstracto, despojado de contexto lingüístico, de forma que no tiene demasiado sentido preguntarse en qué lengua está la inscripción, simplemente podemos preguntarnos a qué lengua corresponde el NP. En otros casos el NP ha sufrido ciertas manipulaciones lingüísticas o, más claramente aún, está acompañado de marcas gramaticales propiamente ibéricas, con lo que podemos asegurar que el portador de ese NP no ibérico no sólo se expresa por medio de la escritura ibérica sino en lengua ibérica. Este tipo de información, que encontramos en las inscripciones de propiedad, nos permite empezar a vislumbrar la complejidad étnica de lo que llamamos mundo ibérico, y a advertir que con probabilidad la lengua de las inscripciones ibéricas no es la lengua vernácula de todos sus usuarios sino una lengua vehicular que ha alcanzado una posición privilegiada por razones sociales y económicas, como lengua de la comunidad que primero ha sentido la necesidad de utilizar la escritura en el este de la Península ${ }^{71}$.

Es este uno de los aspectos en los que los humildes grafitos pueden aportar información histórica profunda. Otro es el de la historia económica en el que ya me detuve en el artículo anterior al tratar de los grafitos púnicos y griegos, donde insistí en el interés y las dificultades de identificación e interpretación de los grafitos mercantiles ${ }^{72}$. Los mismos problemas se plantean en el caso de los grafitos ibéricos pero, como ya hemos visto, multiplicados por nuestra ignorancia de la lengua; sólo estudios detallados en un marco concreto, por ejemplo un yacimiento determinado excavado en extensión, podrán ir resolviendo los problemas; tal vez algún día contemos con un pecio en aguas ibéricas que nos permita comprobar una situación similar a la de El Sec, con sus grafitos

\footnotetext{
${ }^{69}$ Untermann: 1979: "Eigennamen”, 60-1; de Hoz: 1993: "La lengua", 653-5.

${ }^{70}$ He reunido los testimonios en de Hoz: 2005: "Epigrafías".

${ }^{71}$ de Hoz: 1993 :"La lengua"; 1994: "Griegos". La noción del ibérico como lengua vehicular ha dado recientemente lugar a cierta polémica, como pudo advertirse en varias de las comunicaciones presentadas al IX Coloquio Internacional sobre Lenguas y Culturas Paleohispánicas celebrado en Barcelona en octubre del 2004 (vid. ahora Actas IX), así como las discusiones a que dieron lugar. En todo caso los argumentos presentados en contra de la teoría no me parecen suficientes para negarle el caracter de hipótesis de trabajo más económica y verosímil.

${ }^{72}$ Vid. también de Hoz: e. p.: "Epigrafía"; e. p.: "La récep-
} tion". mercantiles griegos y púnicos, pero en la que los grafitos ibéricos indiquen una redistribución de cabotaje de cerámicas griegas llegadas previamente a la Península en navíos púnicos, griegos o mixtos.

\section{ADDENDUM A AESPA 75, 2002, 75-91.}

Desde la publicación del artículo que constituye la primera parte de éste no ha habido grandes descubrimientos de epigrafía cerámica fenicia o griega ${ }^{73}$, aunque hay que mencionar la publicación de los primeros grafitos fenicios procedentes de Portugal ${ }^{74}$. Lo más significativo sin duda son los grafitos fenicios publicados en González de Canales, F., Serrano, L. \& Llompart, J.: 2004: El emporio, 133-5, láms. XXXV.1-11, LXI.1-10; las inscripciones han sido estudiadas por M. Heltzer, que subraya con razón el extraordinario arcaismo de algunos signos; por lo demás se trata de textos fragmentarios que, sin apartarse de lo planteado en el artículo que precede a éste, en general no permiten precisiones claras, excepto el $n^{\circ} 8$ sobre el que volveré enseguida; por otra parte dos de estos grafitos no son cerámicos sino sobre hueso y marfil, en ambos casos de lectura más precisa; el primero, $\mathrm{n}^{\circ} 9$, tiene una anotación contable; el segundo, $\mathrm{n}^{\circ} 10$, que parece completo y podría ser un NP, no coincide con nada conocido, al igual que les ocurre a los dos signos centrales del primero, que por ir entre la preposición $l$ y el numeral, podrían ser también un NP, "para/de NP 2"; por otra parte el n 8 podría ser, por el paralelo ugarítico, un razonable término fenicio, ys?n, "vino viejo", pero el soporte no es una ánfora ni otro tipo de recipiente sino un cuenco de retícula bruñida interior en el que no esperaríamos una indicación de su contenido, naturalmente cambiante, sino el NP de su propietario, por lo que de nuevo podríamos estar ante un NP ajeno al repertorio fenicio conocido. ¿Estaremos ante NNP indígenas? ¿Formaban parte gentes no fenicias de los grupos de mercaderes que en fecha temprana llegaban al SO de la Península? Obviamente no es posible esperar en un futuro próximo respuestas a estos problemas, a cuya dificultad intrínseca se une la ambigüedad de la escritura fenicia visible por ej. en el hecho de que $y s ? n$ nos proporcione una perfecta transcripción fenicia del NP griego Jasón, precisamente en estos momentos en que en Grecia y oriente se empieza a vislumbrar la posibilidad de que tenga-

\footnotetext{
${ }^{73}$ Sobre la epigrafía fenicia de Hispania en general vid. recientemente Zamora, J. A.: 2004: "Los textos"; 2005: "El nuevo"; 2005: "La práctica".

${ }^{74}$ M. Sznycer en Mayet, F. \& da Silva, C. T.: 2000: Le site, 261-4; Maia, Ma. Garcia Pereira \& da Silva, L. Fraga: 2004: "O culto", 184-6.
} 
mos NNP o comunes griegos en escritura consonántica fenicia ${ }^{75}$.

Pero al margen de los NNP, el aspecto más interesante de estos grafitos, en lo que coinciden con el testimonio mucho más abundante y preciso del restante material con el que han aparecido, es el de la cronología. A pesar de la precaución con que hay que manejar las fechas paleográficas creo que, con toda prudencia, hay que admitir que alguno de ellos difícilmente puede ser posterior al s. IX; es el caso en particular del $\mathrm{n}^{\circ} 2$, sobre el que ya ha llamado la atención Heltzer ad loc. Desde hace algún tiempo son frecuentes las propuestas de levantar la cronología de la presencia fenicia en Hispania ${ }^{76}$ y el libro en que se contienen estos grafitos constituye una importante aportación de materiales que apuntan en esa dirección, como ha puesto de relieve Torres ${ }^{77}$. Desde el punto de vista de la epigrafía paleohispánica, que según creo en modo alguno puede ser posterior al s. VII y tiene su modelo en la escritura consonántica fenicia, el que durante el s. VIII algunos sectores de las sociedades indígenas hubiesen podido familiarizarse con ésta no constituye un problema sino todo lo contrario.

\section{BIBLIOGRAFÍA}

ACTAS I: 1976: Actas del I Coloquio sobre lenguas y culturas prerromanas de la Península Ibérica (Salamanca, 1974), Salamanca.

ACTAS II:1979: Actas del II Coloquio sobre lenguas y culturas prerromanas de la Península Ibérica (Tübingen, 1976), Salamanca.

ACTAS III: 1985: Actas del III Coloquio sobre lenguas y culturas paleohispánicas (Lisboa, 1980), Salamanca.

ACTAS IV: 1987: Actas del IV Coloquio sobre lenguas y culturas paleohispánicas (Vitoria, 1985), Vitoria/ Gasteiz = Studia Paleohispanica, Veleia 2-3.

ACTAS V: 1993: Actas del V Coloquio sobre lenguas y culturas prerromanas de la Península Ibérica (Colonia 1989) = Lengua y cultura en la Hispania prerromana, Salamanca.

ACTAS VI: 1995: La Hispania Prerromana $=$ Actas del VI Coloquio sobre Lenguas y Culturas Prerromanas de la Península Ibérica (Coimbra 1994), Salamanca.

ACTAS VII: 1999: Pueblos, lenguas y escrituras en la Hispania prerromana. Actas del VII coloquio sobre lenguas y culturas paleohispánicas (Zaragoza 1997), Salamanca.

\footnotetext{
${ }^{75}$ Kenzelmann Pfyffer, A., Theurillat, Th. \& Verdan, S.: 2005: "Graffiti", 76-7.

${ }^{76}$ Aubet, M ${ }^{\text {a E.: }}$ 19942: Tiro, 321-3; Torres, M.: 1998: "La cronología"; Mederos, A.: 2005: "La cronología".

77 Torres: 2005: "Tartesios".
}

ACTAS VIII: 2001: Religión, lengua y cultura prerromanas de Hispania = Actas del VIII Coloquio Internacional sobre Lenguas y Culturas Prerromanas de la Península Ibérica, Salamanca.

ACTAS IX: 2005: Actas del IX coloquio sobre lenguas y culturas paleohispánicas (= Paleohispanica 5), Zaragoza.

ALMAGRO-GORBEA, M.: 1977: El Bronce Final y el Período Orientalizante en Extremadura, Madrid (Capítulo VIII, "La Epigrafía”, 263-77).

1992: "Las necrópolis ibéricas en su contexto mediterráneo", Blánquez, J. \& Antona V. coordinadores: 1992: Congreso, 37-75.

2002: Epigrafía prerromana, Madrid.

2004: "Inscripciones y grafitos tartésicos de la necrópolis orientalizante de Medellín”, Paleohispanica 4, 13-44.

ARANEGUI, C. ed.: 2000: Argantonio. Rey de Tartessos, Sevilla.

ARTEAGA, O. \& CORREA, J. A.: 1994: "Inscripción vascular indígena hallada en Obulco (Porcuna, Jaén) y su contexto arqueológico", Homenaje J.M. Blázquez II, 45-58.

AUBET, M ${ }^{\mathrm{a}}$ E.: 1994²: Tiro y las colonias fenicias de occidente, Barcelona.

AUBET, Ma . E., ed.: 1989: Tartessos, Barcelona.

BEIRÃO, C. M. DE MELLO \& M. VARELA GOMES: 1985: "Grafitos da Idade do Ferro do Centro e Sul de Portugal", Actas III, 465-99.

BLÁNQUEZ, J. \& ANTONA V. coordinadores: 1992: Congreso de arqueología ibérica: las necrópolis, Madrid.

BLÁZQUEZ, J. Mª, et alii: 1970: Huelva arqueológica. Las cerámicas del Cabezo de San Pedro, Huelva.

CABRERA, P., OLMOS R. \& SANMARTÍ, E., COORDINADORES: 1994: Iberos y griegos: lecturas desde la diversidad I-II, Huelva (= Huelva arqueológica XIII 1 y 2).

CELESTINO, S. \& JIMÉNEZ, J., eds.: 2005: El período orientalizante. Actas del III Simposio de Arqueología de Mérida: Protohistoria del Mediterráneo Occidental I-II, Mérida (Anejos de AEspA XXXV).

CORREA, J. A.: 1989: "Inscripción vascular indígena hallada en Baeza (Jaén)", APL 19, 183-9. 1993: "Antropónimos galos y ligures en inscripciones ibéricas", Studia palaeohispanica J. Untermann, 101-16.

1996 (1998): “Grafito paleohispánico hallado en el depósito de Garvão (Ourique, Beja)", SPAL 5, 167 70.

CUADRADO, E.: 1987: La necrópolis ibérica de "El Cigarralejo" (Mula, Murcia), Madrid 1987.

DE ULISSES: s. d. (1996): De Ulisses a Viriato. O primeiro milénio a.C., Instituto Português de Museus. 
FARIA, A. MARQUES DE: 1990-91: “Antropónimos em inscrições hispânicas meridionais", Portugalia 11-12, 73-88.

1994: "Subsídios para o estudo da antroponímia ibérica", Vipasca 3, 65-71.

1995: "Algumas notas de onomástica ibérica", Portugalia 16, 323-30.

1997: "Apontamentos sobre onomástica paleohispânica", Vipasca 6, 105-14.

1999: "Novas notas de onomástica hispânica préromana", Revista Portuguesa de Arqueologia 2:1, $153-61$.

2000: "Onomástica paleo-hispânica: revisão de algumas leituras e interpretações", Revista Portuguesa de Arqueologia 3:1, 121-51.

2000: "Crónica de onomástica paleo-hispânica (1)", Revista Portuguesa de Arqueologia 3:2, 61-6.

2001: "Crónica de onomástica paleo-hispânica (2)", Revista Portuguesa de Arqueologia 4:1, 95-107.

2002: "Crónica de onomástica paleo-hispânica (3)", Revista Portuguesa de Arqueologia 5:1, 121-46.

FERNÁNDEZ JURADO, J. \& CORREA, J. A.: 198889: "Nuevos grafitos hallados en Huelva", Huelva arqueológica 10-11, 3, 121-42.

GALLET DE SANTERRE, H.: 1965: "Les civilisations classiques en Languedoc méditerranéen et Roussillon, principalement d'après les fouilles d'Ensérune", Le rayonnement, 625-38.

GARCÍA MARTÍN, J. M.: 2003: La distribución de cerámica griega en la Contestania ibérica: El puerto comercial de la Illeta dels Banyets, Alicante.

GÓMEZ-MORENO, M.: 1949: Misceláneas. Historia, Arte, Arqueología. Primera serie: la antigüedad, Madrid.

GONZÁlEZ DE CANALES, F. \& SERRANO, L.: 1995: "Consideraciones en torno al Tarteso griego y al Tarsis de Salomón con motivo de unos grafitos hallados en Huelva", Revista de Arqueología 16, 175, 8-17.

GONZÁlEZ DE CANALES, F., SERRANO, L. \& LLOMPART, J.: 2004: El emporio fenicio precolonial de Huelva (ca. 900-770 a.C.), Madrid (Biblioteca Nueva).

GONZÁLEZ PRATS, A.: 1982: La Peña Negra IV, NAH 13, Madrid.

1983: Estudio arqueológico del poblamiento antiguo de la Sierra de Crevillente (Alicante), Alicante.

GRECS ET IBÈRES AU IV ${ }^{\mathrm{E}}$ SIÈCLE AVANT JÉSUSCHRIST: 1987: Bordeaux (=REA 89 3-4).

GUTIÉRREZ SOLER, L. M $M^{\mathrm{a}}$ : 2002: El oppidum de Giribaile, Jaén (Universidad).

HERNÁNDEZ HERNÁNDEZ, F.: 1985: "Nuevos grafitos de Extremadura", NAH 20, 221-4.

HERNÁNDEZ HERNÁNDEZ, F. , RODRÍGUEZ, M. ${ }^{a}$ D. \& SÁNCHEZ, M. ${ }^{a}$ A.: 1989: Excavaciones en el
Castro de Villasviejas de Tamuja (Botija, Cáceres), Mérida.

DE HOZ, J.: 1976: "La epigrafía prelatina meridional en Hispania", Actas I, 227-317.

1989: "El desarrollo de la escritura y las lenguas de la zona meridional", M. E. Aubet ed., Tartessos, 523-87.

1993 :'La lengua y la escritura ibéricas, y las lenguas de los íberos", Actas del V Coloquio, 635-66.

1994: "Griegos e íberos. Testimonios epigráficos de una cooperación mercantil", Cabrera, P., Olmos R. \& Sanmartí, E. , Coordinadores, Iberos II, 24371.

1994: "Notas sobre inscripciones meridionales de la Alta Andalucía", Homenaje a J. Mª́ Blázquez II, 16779.

1995: "Tartesio, fenicio y céltico, 25 años después", Tartessos 25 años después, 591-607.

1997: "Catalogue $\mathrm{n}^{\circ}$ 226.1, 268”, P. Rouillard, Antiquités de l'Espagne, Paris, 142-3, 172-3.

1998: "La epigrafía de El Cigarralejo", Ruano coord., Museo de "El Cigarralejo", 219-24.

2002: "Grafitos cerámicos griegos y púnicos en la Hispania prerromana”, AEspA 75, 75-91.

2005: "La recepción de la escritura en Hispania como fenómeno orientalizante", Celestino, S. \& Jiménez, J., eds., El período orientalizante, 363-81. 2005: "Ptolemy and the linguistic history of the Narbonensis", de Hoz, J., Luján, E. R. \& SimsWilliams, P., New Approaches, 173-88.

2005: "Epigrafías y lenguas en contacto en la Hispania antigua", Actas IX, 57-97.

e. p.: "Epigrafía y actividades económicas", Approches archéologiques des écomies antiques. Problèmes méthodologiques et théoriques, Oxford (BAR).

e. p.: "La réception de l'épigraphie héllenistique dans l'extrême occident", L'héllenisation en Méditerranée occidentale au temps des guerres puniques (260-180 av. J.-C.), Toulouse (Pallas 2006).

DE HOZ, J. \& LUJÁN, E. R.: 2001: "Bibliografía de inscripciones ibéricas no recogidas en $M L H$ ", Paleohispanica 1, 355-67.

LES IBÈRES: 1997: Les Ibères, Paris (= Los íberos. Príncipes de occidente : 1998: Barcelona = Die Iberer: 1998: Bonn).

JANNORAY, J.: 1955: Ensérune. Étude des civilisations préromaines de la Gaule méridionale, Paris.

LLOBREGAT, E.: 1972, Contestania Iberica, Alicante, (inscripciones en pp. 117-31).

1989: "Los "graffiti" en escritura grecoibérica y púnica de la Illeta dels Banyets, El Campeyo (Alicante)", APL 19, 149-66.

1993: "L'Illeta dels Banyets (El Campello, Camp d'Alacant) ¿fou un empórion ?", Homenatge Tarradell, 421-8. 
KENZELMANN PFYFFER, A., THEURILLAT, TH. \& VERDAN, S.: 2005: "Graffiti d'époque géométrique provenant du sanctuaire d'Apollon Daphnéphoros à Erétrie", ZPE 151, 51-86.

LORRIO, A. J.: 1988-89: "Cerámica gris orientalizante de la necrópolis de Medellín (Badajoz)", Zephyrus 41-42, 283-314.

MAIA, M. ${ }^{\mathrm{a}}$ GARCÍA PEREIRA \& DA SILVA, L. FRAGA: 2004: "O culto de Baal en Tavira", Huelva Arqueológica 20, 171-94.

MALUQUER DE MOTES, J.: 1968: Epigrafía prelatina de la Península Ibérica, Barcelona.

MATA, C. \& SORIA, L.: 1997: "Marcas y epígrafes sobre contenedores de época ibérica", Archivo de Prehistoria Levantina 22, 297-374.

MAYET, F. \& DA SILVA, C. T.: 2000: Le site phénicien d'Abul (Portugal). Comptoir et sanctuaire, Paris (de Boccard).

MEDEROS, A.: 2005: "La cronología fenicia. Entre el Mediterráneo oriental y el occidental", Celestino, S. \& Jiménez, J., El período orientalizante I, 30546

MEDEROS, A. \& RUIZ CABRERO, L.: 2001: "Los inicios de la escritura en la Península Ibérica. Grafitos en cerámicas del Bronce Final III y fenicias", Complutum 12, 97-112.

2000-1: "Transhumancia, sal y comercio fenicio en las cuencas de los ríos Vinalapó y Bajo Segura (Alicante)", Lucentum 19-20, 83-94.

MLH = Untermann, 1975..., Monumenta .

PANOSA, Ma I.: 1993: "Nuevas inscripciones ibéricas de Cataluña”, Complutum 4, 175-222.

1999: La escritura ibérica en Cataluña y su contexto socioeconómico (siglos V-I a. C.), Vitoria.

PELLICER, M.: 1987-88: "La cerámica a mano del Bronce reciente y del orientalizante en Andalucía occidental", Habis 18-19, 461-83.

LE RAYONNEMENT DES CIVILISATIONS GRECQUE ET ROMAINE SUR LES CULTURES PÉRIPHÉRIQUES: 1965: $8^{\text {me }}$ Congrès International d'Archéologie Classique (1963). Actes, Paris.

ROCHA, A. DOS S.: 1908: "Estaçôes Pre-Romanas da Idade do Ferro nas visinhanças da Figueira", Portugalia 2.

RODRÍGUEZ RAMOS, J.: 1997: "Primeras observaciones para una datación paleográfica de la escritura ibérica", AEspA 70, 13-30.

2000: "Nuevas observaciones de crono-paleografía ibérica levantina", AEspA 73, 43-57.

2002: "La inscripción sobre escultura del Cerro de los Santos G.14.1 y los problemas de homomorfia en la escritura íbera meridional", Habis 33, 203-11. 2002: "Problemas y cuestiones metodológicas en la identificación de los compuestos de tipo onomástico de la lengua íbera", Arse 36, 15-50.
2002: "Índice crítico de los formantes de compuesto de tipo onomástico en la lengua íbera", Cypsela 14, 251-75.

2004: Análisis de epigrafía íbera, Vitoria (Veleia. Anejos s. mi. 22).

RUANO, E. coord.: 1998: Museo de "El Cigarralejo", Mula, Murcia, Madrid.

RUIZ CABRERO, L. A. \& LÓPEZ PARDO, F.: 1996: "Cerámicas fenicias con graffiti de la isla de Essaouira (antigua Mogador, Marruecos)", RSF 24, 153-79.

RUIZ MATA, D.: 1979: "El Bronce Final —fase inicial- en Andalucía occidental. Ensayo de definición de sus cerámicas", AEspA 52, 31-19.

SCHUBART, H.: 1971: "Acerca de la cerámica del Bronce Tardío en el sur y oeste penindular", Trabajos de Prehistoria 28, 153-82.

SCHUCHARDT, H.: 1909: "Iberische Personennamen", RIEV 3, 237-47.

SOLIER, Y.: 1978: "Les oppida du Languedoc "ibérique": aperçu sur l'évolution du groupe narbonnais", 2 Col.loqui Els pobles pre-romans del Pirineu, 153-67.

1979: "Découverte d'inscriptions sur plombs en écriture ibérique dans un entrepot de Pech Maho (Sigean)", RAN 12, 55-123.

SOLIER, Y. \& BARBOUTEAU, H.: 1988 (= 1990): "Découverte de nouveaux plombs, inscrits en ibère, dans la region de Narbonne", RAN 21, 61-94.

STUDIA PALAEOHISPANICA: 1993: Studia palaeohispanica et indogermanica J. Untermann ab amicis hispanicis oblata, I. J. Adiego, J. Siles, \& J. Velaza edd., Barcelona.

TARTESSOS 25 AÑOS DESPUÉS: 1995: Actas del Congreso Conmemorativo del V Symposium Internacional de Prehistoria Peninsular, Jerez de la Frontera.

TORRES, M.: 1998: "La cronología absoluta europea y el inicio de la colonización fenicia en Occidente. Implicaciones cronológicas en Chipre y el Próximo Oriente", Complutum 9, 49-60.

2002: Tartessos, Madrid.

2005: "Tartesios, Fenicios y Griegos en el Sudoeste de la Península Ibérica: algunas reflexiones sobre los recientes hallazgos de Huelva", Complutum 16, 292304.

UNTERMANN, J.: 1969: "Lengua ibérica y lengua gala en la Galia Narbonensis", APL 12, 99-161. 1975/1980/1990/1997: Monumenta Linguarum hispanicarum. I. Die Münzlegenden. II. Inschriften in iberischer Schrift aus Südfrankreich. III. Die iberischen Inschriften aus Spanien. IV. Die tartessischen, keltiberischen und lusitanishen Inschriften, Wiesbaden.

1979: "Eigennamen auf iberischen Inschriften", Actas II Coloquio, 41-67. 
1987: "Repertorio antroponímico ibérico", APL 17, 289-318.

2000: "Lenguas y escrituras en torno a Tartessos", Aranegui, C. ed., Argantonio, 68-77.

VAQUERIZO, D., QUESADA, F. \& MURILLO, J. F.: 1992: "La cerámica ibérica del Cerro de la Cruz. Departamentos O, P, N", AAC 3, 51-112.

VELAZA, J.: 1996: "Chronica Epigraphica Iberica: hallazgos de inscripciones ibéricas en Levante, Cataluña, Aragón y Navarra (1989-1994)", Actas del VI Coloquio, 311-337.

2001: "Chronica Epigraphica Iberica II: Novedades y revisiones de epigrafía ibérica (1995-1999)", Actas VIII, 639-662.
2001: "Chronica Epigraphica Iberica III (2000)", Paleohispanica 1, 393-5.

VILLAR, F.: 2000: Indoeuropeos y no indoeuropeos en la Hispania prerromana, Salamanca.

ZAMORA, J. A.: 2004: "Los textos invisibles: la documentación fenicia y la introducción de la escritura en la Península Ibérica", Huelva Arqueológica 20, 299-317. 2005: "El nuevo corpus epigráfico fenicio y las inscripciones fenicias halladas en la península ibérica: estado actual y primeras consideraciones, Celestino, $\mathrm{S}$. \& Jiménez, J., eds. El período orientalizante, 511-8. 2005: "La práctica de escribir entre los primeros fenicios peninsulares y la introducción de la escritura entre los pueblos paleohispánicos”, Actas IX, 155-92.

Recibido el 18-04-06 Aceptado el 13-06-06 